\title{
Comparison of choroidal thickness in patients with active and stable thyroid eye disease
}

\author{
Comparação da espessura da coroide em pacientes com doença ocular \\ tireoidiana ativa e estável
}

Adem Gul', Ekrem Basural', Hilal Eser Ozturk'

1. Ophthalmology Department, Ondokuz Mayis University, Samsun, Turkey.

\begin{abstract}
Purpose: To compare the choroidal thickness in active and stable phases of thyroid eye disease. Methods: Forty-seven eyes of 47 patients with thyroid eye disease were prospectively studied. Patients were evaluated on the basis of their clinical activity scores, with scores $\geq 3$ defined as active disease. Subfoveal, temporal macular, nasal macular, temporal peripapillary, and nasal peripapillary choroidal thickness measurements were performed with Cirrus enhanced depth imaging spectral-domain optical coherence tomography, and the results in the two groups were compared. Results: Twenty-four patients were int he active group, whereas 23 patients were in the stable group. Choroidal thickness was significantly higher in the subfoveal and temporal macular regions in the active group. Although the nasal macular and peripapillary values were also higher in the active group, the difference was insignificant. Conclusions: Subfoveal choroidal thickness was significantly higher in patients with thyroid eye disease in the active phase than in those with stable phase disease.
\end{abstract}

Keywords: Graves ophthalmopathy; Choroid/anatomy \& histology; Tomography, optical coherence

RESUMO | Objetivo: Comparar a espessura da coroide nas fases ativa e estável da doença ocular tireoidiana. Métodos: Quarenta e sete olhos, de 47 pacientes com doença ocular tireoidiana foram estudados prospectivamente. Os pacientes foram avaliados com base em seus escores de atividade clínica, com escore de $\geq 3$ definidos como doença ativa. As medidas subfoveais, maculares temporais, maculares nasais, peripapilares temporais e da espessura da coroide peripapilar foram realizadas com tomografia de coerência óptica de domínio espectral Cirrus EDI, e os resultados

Submitted for publication: February 6, 2018

Accepted for publication: June 22, 2018

Funding: No specific financial support was available for this study.

Disclosure of potential conflicts of interest: None of the authors have any potential conflicts of interest to disclose.

Corresponding author: Adem Gul

Ophthalmology Department - Ondokuz Mayis Universitesi, Tip Fakultesi, Goz Hastaliklari 55139 Kurupelit Atakum - Samsun - Turkey - E-mail: drademgul@gmail.com

Approved by the following research ethics committee: Ondokuz Mayis University (\# 2015/291). nos dois grupos foram comparados. Resultados: Vinte e quarto pacientes estavam no grupo ativo, enquanto 23 pacientes estavam no grupo estável. A espessura da coroide foi significativamente maior nas regiões macular subfoveal e temporal no grupo ativo. Embora os valores maculares e peripapilares nasais também fossem maiores no grupo ativo, a diferença foi insignificante. Conclusões: A espessura da coroide subfoveal foi significativamente maior em pacientes com doença ocular tireoidiana na fase ativa do que naqueles com doença na fase estável.

Descritores: Oftalmopatia de Graves; Coroide/anatomia \& histologia; Tomografia de coerência óptica

\section{INTRODUCTION}

Thyroid eye disease (TED) is a disease characterized by the inflammation and extreme remodeling of the tissues around the eye and develops in $25 \%-50 \%$ of patients with Graves' disease ${ }^{(1,2)}$. TED is thought to be an organ-specific autoimmune inflammatory disease caused by antibodies that stimulate thyrotropin receptors ${ }^{(2,3)}$. The course of the disease is biphasic, with an initial active phase followed by a stable phase. The active phase consists of inflammatory findings including swelling and redness of the conjunctiva and the eyelids.

The choroid is responsible for metabolic support of the retinal pigment epithelium, blood flow in the preliminary part of the optic nerve, regulation of light absorption, and heat regulation of the retina. Thus, it plays an important role in the pathophysiology of many inflammatory and non-inflammatory diseases that affect the retina ${ }^{(4)}$.

Studies on the utility of enhanced depth imaging spectral-domain optical coherence tomography (EDI-OCT), a relatively new technique for in vivo cross-sectional imaging of the choroid, have garnered interest for the diagnosis and treatment of many inflammatory and non-inflammatory diseases. 
Since inflammation can induce changes in choroidal circulation, this study was conducted to compare the choroidal thickness in patients with active and stable phases of TED.

\section{METHODS}

The study was carried out prospectively between the years of 2015 and 2016. EDI-OCT images were obtained from all TED patients treated in a tertiary referral center. Forty-seven patients were evaluated, and clinical severity was assessed using the clinical activity scoring (CAS) system described by Mourits et al. ${ }^{(5)}$. Ten parameters, namely, pain behind the globe, pain on attempted gaze, redness of the eyelid(s), diffuse redness of the conjunctiva, chemosis, swollen caruncule, edema of the eyelid(s), increase of proptosis by $2 \mathrm{~mm}$ or more during a period between 1 and 3 months, decrease in visual acuity of one or more lines on the Snellen chart (using a pinhole) during a period between 1 and 3 months, and decrease of eye movements in any direction equal to or greater than $5^{\circ}$ during a period between 1 and 3 months were used to evaluate the activity. CAS results can range from 0 to 10 , and values $\geq 3$ were defined as active disease. The patients were assessed according to CAS and separated into two groups for active and stable diseases. The active and stable groups comprised 24 and 23 patients, respectively.

Myopic refractive error greater than -5 diopters or hyperopic refractive error greater than +3 diopters, optic disc anomaly, vitreoretinal interface disease, vascular and degenerative diseases of the retina, presence of corneal opacity, presence of lens opacity, history of ocular surgery, neurological diseases that may affect the visual field, trauma history, and the presence of anterior and posterior segment diseases such as amblyopia, diplopia, uveitis, and keratitis were determined as exclusion criteria.

Detailed history information was obtained from all patients, and detailed ophthalmologic examinations, which consisted of best-corrected visual acuity, slit-lamp biomicroscopy, intraocular pressure measurement with Goldmann applanation tonometry in a sitting position, and dilated fundus examination, were performed on each patient. The degree of proptosis was examined with a Hertel exophthalmometer. All patients were also evaluated using orbital MRI to observe extraocular muscle involvement.

Optical coherence tomography assessment was performed with a Cirrus HD-OCT (Carl Zeiss Meditec Inc., Dublin, CA, USA) with no need for pupil dilation. An HD 5 Line Raster protocol with intervals of $0.25 \mathrm{~mm}$, which consisted of $6 \mathrm{~mm}$ parallel lines of 1024 A-scanning/
B-scanning, was applied in the study. The choroid was scanned using Cirrus HD-OCT with EDI mode. Patients with a signal quality of 6 and below were excluded from the study.

Macular and peripapillary sections were evaluated. Images from the macular section were magnified, and subfoveal choroidal thickness was measured as defined by Spaide et al. ${ }^{(6)}$.

A total of 13 measurements were taken for the calculation of average choroidal thickness for the macular region. The average choroidal thickness values for the nasal macular and temporal macular areas were calculated from average measurements of the right eye at $500 \mu \mathrm{m}$ intervals, up to $3000 \mu \mathrm{m}$ temporal and nasal to the fovea. The average choroidal thickness values of nasal peripapillary and temporal peripapillary areas were calculated from average measurements of the right eye at $500 \mu \mathrm{m}$ intervals, up to $2000 \mu \mathrm{m}$ temporal and nasal to the optic nerve head (Figure 1). In all patients, choroidal thickness measurements were performed by two different clinicians and the average results were used for analysis.

Written consent was obtained from all participants in the study in accordance with the World Medical Association October 2008 Declaration of Helsinki, and ethical approval was granted by the clinical research ethical board.

\section{Statistical analysis}

The SPSS v.22 program was used for data analysis. The results were presented as frequency and percentage (\%) in categorical variables and as average \pm standard deviation or median (minimum-maximum) for continuous variables for demographic data (gender, age, etc.). The significance of the choroidal thickness was tested with independent $t$-tests between the two groups, and the correlation was tested with bivariate analysis. Statistical significance was accepted at $p$ values $<0.05$.

\section{RESULTS}

The demographic data for the study, which included 47 participants, are given in table 1.

Of the 24 patients in the active group, 18 (75\%) were diagnosed with Graves' disease, 3 (12.5\%) were diagnosed with nodular goiter, and 3 (12.5\%) were diagnosed with Hashimoto's thyroiditis. Of the 23 patients in the stable group, 17 (74\%) were diagnosed with Graves' disease, 3 (13\%) were diagnosed with nodular goiter, and 3 (13\%) were diagnosed with Hashimoto's thyroiditis. 
Clinical findings for the patients are summarized in table 2 as well as the Hertel exophthalmometry values and comparisons between the groups. The mean value for the stable group was lower than that for the active group, but the difference was insignificant $(p=0.06)$.

Orbital MR images showed different degrees of extraocular muscle involvement in all patients.

In ophthalmic examination, a mild decline in vision and minimal optic nerve paleness were detected in
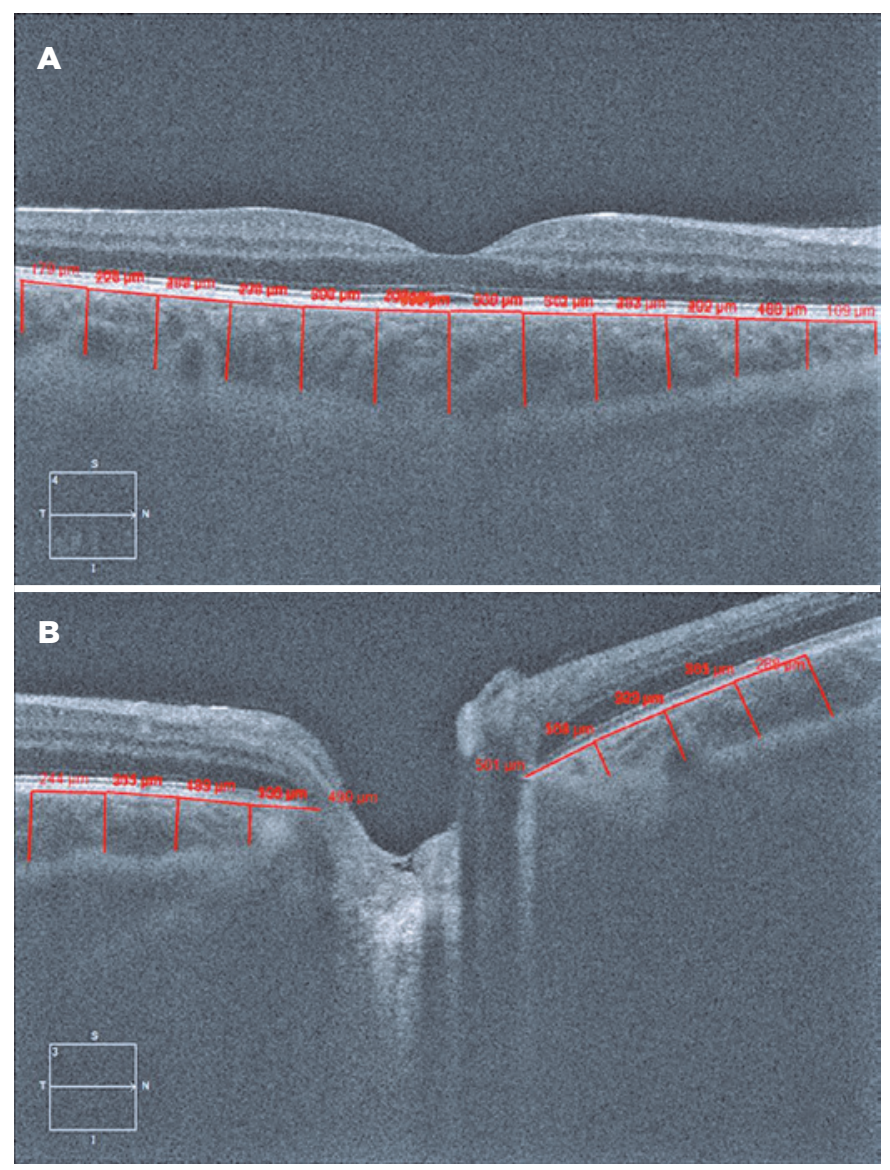

Figure 1. A) The choroidal thickness was measured at 13 points with $500 \mu \mathrm{m}$ intervals, up to $3000 \mu \mathrm{m}$ temporal and nasal to the fovea. B) The choroidal thickness was measured at 8 points with $500 \mu \mathrm{m}$ intervals, up to $2000 \mu \mathrm{m}$ temporal and nasal to the optic nerve head.

Table 1. Demographical data for the groups

\begin{tabular}{lcc}
\hline & Stable & Active \\
\hline Number of cases (n/eyes) & $23 / 47$ & $24 / 47$ \\
Gender & & \\
Women & $19(82.6 \%)$ & $15(62.5 \%)$ \\
Men & $4(17.4 \%)$ & $9(37.5 \%)$ \\
Age & & \\
(Average \pm SD, years) & $43.7 \pm 11.9$ & $40.7 \pm 11.8$ \\
(Min-max) & $18-56$ & $22-60$ \\
\hline
\end{tabular}

three patients in the active group and in two patients in the stable group who had optic nerve involvement. In other patients in the active group, the best-corrected visual acuity was $20 / 20$ and fundus examinations were assessed as normal. Mild punctate epitheliopathy due to corneal exposure was found in two patients with corneal involvement.

Table 3 shows the nasal macular, temporal macular, nasal peripapillary, temporal peripapillary, and subfo-

Table 2. Clinical findings for thepatients in both groups

\begin{tabular}{|c|c|c|}
\hline & Stable & Active \\
\hline Eyelid retraction & 13 & 19 \\
\hline Corneal involvement & 1 & 1 \\
\hline Restricted eye movements & 3 & 1 \\
\hline Optic nerve involvement & - & - \\
\hline Diplopia & 0 & 3 \\
\hline Color vision disorder & 0 & 0 \\
\hline Steroid use & 1 & 9 \\
\hline Decompression surgery & 2 & - \\
\hline \multicolumn{3}{|l|}{ Exophthalmus of right eye } \\
\hline (Average $\pm \mathrm{SD}$ ) & $20.30 \pm 2.10$ & $21.50 \pm 2.00$ \\
\hline (Median-min-max) & $19-18-25$ & $21-19-27$ \\
\hline \multicolumn{3}{|l|}{ Exophthalmus of left eye } \\
\hline$($ Average $\pm \mathrm{SD})$ & $20.60 \pm 2.20$ & $21.90 \pm 2.40$ \\
\hline (Median-min-max) & $20-17-25$ & $21-19-28$ \\
\hline \multicolumn{3}{|l|}{ CAS (clinical activity score) } \\
\hline (Average $\pm \mathrm{SD}$ ) & $0.65 \pm 0.71$ & $4.33 \pm 1.43$ \\
\hline (Median-min-max) & $1-0-2$ & $4-3-7$ \\
\hline
\end{tabular}

Table 3. Comparison of average right eye choroidal thickness between the groups

\begin{tabular}{lccc}
\hline & Stable & Active & p-value \\
\hline Subfoveal & & & \\
(Average $\pm \mathrm{SD}, \mu \mathrm{m})$ & $262.04 \pm 63.46$ & $304.79 \pm 75.19$ & 0.04 \\
(Median-min-max) & $246-175-384$ & $315-168-425$ & \\
Nasal macular & & & \\
(Average $\pm \mathrm{SD}, \mu \mathrm{m})$ & $178.26 \pm 62.83$ & $199.75 \pm 47.63$ & 0.19 \\
(Median-min-max) & $162-87-325$ & $192-100-303$ & \\
Temporal macular & & & 0.01 \\
(Average $\pm \mathrm{SD}, \mu \mathrm{m})$ & $234.13 \pm 57.28$ & $279.67 \pm 61.89$ & \\
(Median-min-max) & $229-138-350$ & $268-152-382$ & \\
\hline Nasal peripapillary & & & 0.55 \\
(Average $\pm \mathrm{SD}, \mu \mathrm{m})$ & $207.87 \pm 79.65$ & $219.88 \pm 53.67$ & \\
(Median-min-max) & $201-78-394$ & $213-116-314$ & \\
\hline Temporal peripapillary & & & \\
\hline (Average \pm SD, $\mu \mathrm{m})$ & $173.43 \pm 59.66$ & $194.12 \pm 39.27$ & \\
(Median-min-max) & $158-68-286$ & $194-115-272$ & \\
\hline
\end{tabular}


veal average choroidal thickness values as well as the median-minimum-maximum values of the right eyes for all the patients. Subfoveal choroidal thickness and temporal macular choroidal thickness values showed significant differences between the groups, with $p$ values of 0.04 and 0.01 , respectively.

There was no statistical correlation between the CAS and choroidal thickness $(p=0.64)$.

\section{DISCUSSION}

Thyroid ophthalmopathy has been known for more than 200 years. The most common clinical findings are proptosis, upper eyelid retraction, edema, and erythema in periorbital tissues. The disease has a bimodal incidence within the 40s and 60s age ranges. It is more common in women, and symptom onset occurs at the age of 40 to 44 years $^{(7)}$. In this study as well, most of the patients were women $(72 \% / 28 \%)$.

Orbital fibroblast activity is thought to play an important role in the onset and continuation of the disease. When these orbital fibroblasts are stimulated, they produce inflammatory mediators, turn into adipocytes and fibroblasts, and increase extracellular matrix production $^{(1,2,8)}$. Proptosis develops as a result of the expansion of orbital fat and muscle tissues in the bone structure. In our study, Hertel exophthalmometry values were higher in the active group without statistical significance.

In TED, the most severe consequence of increased content and pressure in the orbit is compressive optic neuropathy. Optic disc paleness and mild low vision were found in five of the patients in the study. In the literature, the frequency of serious involvement such as corneal ulcer or optic neuropathy that threatens vision in patients with TED has been reported as $3 \%-5 \%{ }^{(9)}$.

EDI-OCT, a relatively new technique that allows in vivo cross-sectional imaging of the choroid, was described for the first time by Spaide et al. in 2008. In this technique, the eye is brought closer to the device and a reverse image is obtained. Thus, the visibility of deeper structures is increased by moving the structures closer to the zero point ${ }^{(6)}$. High correlation was found between measurements obtained with different tools ${ }^{(10,11)}$.

Measuring the choroidal thickness with EDI-OCT is gradually becoming the standard method for assessing ocular disease. The use of choroidal thickness in central serous chorioretinopathy, age-related macular degeneration, polypoidal choroidal vasculopathy, inflammatory diseases such as Vogt-Koyanagi-Harada, and systemic diseases is also increasing gradually ${ }^{(12-15)}$.
The choroid is the thickest section in the subfoveal area, and subfoveal choroidal thickness decreases with age $^{(14,16)}$. Some studies have reported that the thickness tends to decrease at the nasal and temporal regions, whereas other studies have reported that temporal thickness is greater than subfoveal thickness, especially in patients with high myopia ${ }^{(16-18)}$. In our study, subfoveal choroidal thickness was the highest, followed by the temporal macular, nasal peripapillary, nasal macular, and temporal peripapillary regions.

In our study, subfoveal choroidal thickness measurements in the stable group were lower compared with other studies in the literature ${ }^{(16,17,19,20)}$. The most important reason for this may be the fact that $80 \%$ of our patients were women. Li et al. found that the choroid was $18 \%$ thinner in women than in men ${ }^{(19)}$.

Studies involving choroidal thickness in TED are very rare. In one of these studies, Özkan et al. found significantly higher choroidal thickness in patients with TED compared with the control subjects ${ }^{(21)}$. They postulated that choroidal thickness was increased because of orbital venous congestion and increased intraorbital pressure related to expanded orbital tissues.

In this study, we compared choroidal thickness in active and stable patients with TED. To our best knowledge, this study may be the first comparison of choroidal thickness in active and stable patients with TED based on the results of our PubMed database search with the keywords "thyroid, choroidal thickness, ophthalmopathy, orbitopathy, Graves' disease, hyperthyroidism, thyroid eye disease, thyroid associated ophthalmopathy."

Subfoveal and temporal macular choroidal thickness values were significantly higher in the active group than in the stable group. As stated earlier, TED is an autoimmune inflammatory disease that affects the orbits. In the active stage, apparent inflammation can be observed, followed by a stable phase. Choroidal thickness is known to increase in some inflammatory diseases. A possible explanation for the higher choroidal thickness in the active group is increased intraorbital pressure leading to impaired venous drainage. Although TED is not associated with symptoms of intraocular-uveal inflammation, the inflammatory nature of thyroid ophthalmopathy may lead to an increase in choroidal thickness with a low possibility.

There was a significant difference in the subfoveal choroidal thickness between the groups. Though there was no significant difference in nasal macular and peripapillary thickness, as can be seen in table 3, all values were higher in the active group than in the control group. 
A possible explanation is lower expandability due to the lower choroidal thickness in the peripapillary area compared with the subfoveal and temporal macular regions.

Choroidal thickness may change with inflammatory activity. One of the limitations in this study was that no correlation was found between the choroidal thickness and activity score due to the small number of patients and the lack of equal distribution of activity scores. Two thirds of the patients had scores within a range of 3 to 4 .

In conclusion, subfoveal choroidal thickness was significantly higher in active TED compared with the stable phase. To correlate choroidal thickness and CAS, large series studies are needed.

\section{REFERENCES}

1. Bahn RS. Graves' ophthalmopathy. N Engl J Med. 2010;362(8):726-38.

2. Dik WA, Virakul S, van Steensel L. Current perspectives on the role of orbital fibroblasts in the pathogenesis of Graves' ophthalmopathy. Exp Eye Res. 2016;142(1):83-91.

3. Cooper DS. Hyperthyroidism. Lancet. 2003;362(9382):459-68.

4. Nickla DL, Wallman J. The multifunctional choroid. Prog Retin Eye Res. 2010;29(2):144-68.

5. Mourits MP, Koornneef L, Wiersinga WM, Prummel MF, Berghout A, van der Gaag R. Clinical criteria for the assessment of disease activity in Graves' ophthalmopathy: a novel approach. Br J Ophthalmol. 1989;73(8):639-44.

6. Spaide RF, Koizumi H, Pozzoni MC. Enhanced depth imaging spectral-domain optical coherence tomography. Am J Ophthalmol. 2008;146(4):496-500.

7. Bartley GB. The epidemiologic characteristics and clinical course of ophthalmopathy associated with autoimmune thyroid disease in Olmsted County, Minnesota. Trans Am Ophthalmol Soc. 1994; 92:477-588.

8. Bahn RS. Clinical review 157: Pathophysiology of Graves' ophthalmopathy: the cycle of disease. J Clin Endocrinol Metab. 2003; 88(5):1939-46
9. Wiersinga WM, Bartalena L. Epidemiology and prevention of Graves' ophthalmopathy. Thyroid. 2002;12(10):855-60.

10. Yamashita T, Yamashita T, Shirasawa $M$, Arimura N, Terasaki $H$, Sakamoto T. Repeatability and reproducibility of subfoveal choroidal thickness in normal eyes of Japanese using different SD-OCT devices. Invest Ophthalmol Vis Sci. 2012;53(3):1102-7.

11. Branchini L, Regatieri CV, Flores-Moreno I, Baumann B, Fujimoto JG, Duker JS. Reproducibility of choroidal thickness measurements across three spectral domain optical coherence tomography systems. Ophthalmology. 2012;119(1):119-23.

12. Imamura Y, Fujiwara T, Margolis R, Spaide RF. Enhanced depth imaging optical coherence tomography of the choroid in central serous chorioretinopathy. Retina. 2009;29(10):1469-73.

13. Chung SE, Kang SW, Lee JH, Kim YT. Choroidal thickness in polypoidal choroidal vasculopathy and exudative age-related macular degeneration. Ophthalmology. 2011;118(5):840-5.

14. Nakayama M, Keino H, Okada AA, Watanabe T, Taki W, Inoue M et al. Enhanced depth imaging optical coherence tomography of the choroid in Vogt-Koyanagi-Harada disease. Retina. 2012;32(10): 2061-9.

15. Tan KA, Gupta P, Agarwal A, Chhablani J, Cheng CY, Keane PA et al. State of science: choroidal thickness and systemic health. Surv Ophthalmol. 2016;61(5):566-81.

16. Margolis R, Spaide RF. A pilot study of enhanced depth imaging optical coherence tomography of the choroid in normal eyes. Am J Ophthalmol. 2009;147(5):811-5.

17. Manjunath V, Taha M, Fujimoto JG, Duker JS. Choroidal thickness in normal eyes measured using Cirrus HD optical coherence tomography. Am J Ophthalmol. 2010;150(3):325-329.e1.

18. Fujiwara T, Imamura Y, Margolis R, Slakter JS, Spaide RF. Enhanced depth imaging optical coherence tomography of the choroid in highly myopic eyes. Am J Ophthalmol. 2009;148(3):445-50.

19. Li XQ, Larsen M, Munch IC. Subfoveal choroidal thickness in relation to sex and axial length in 93 Danish university students. Invest Ophthalmol Vis Sci. 2011;52(11):8438-41.

20. Karaca EE, Özdek Ş, Yalçin NG, Ekici F. Reproducibility of choroidal thickness measurements in healthy Turkish subjects. Eur J Ophthalmol. 2014;24(2):202-8.

21. Özkan B, Koçer CA, Altintaş Ö, Karabaş L, Acar AZ, Yüksel N; Medscape. Choroidal changes observed with enhanced depth imaging optical coherence tomography in patients with mild Graves orbitopathy. Eye (Lond). 2016;30(7):917-24. 